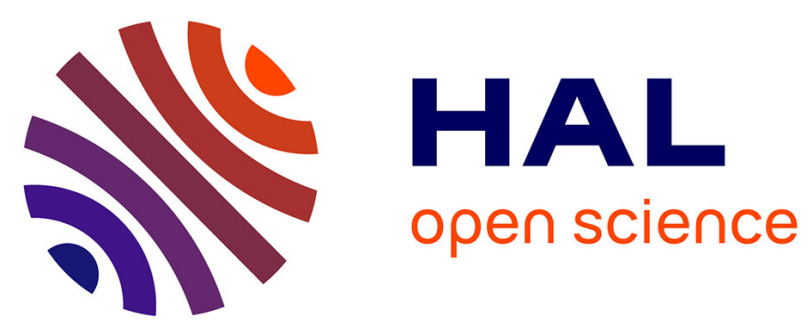

\title{
Use of a Ring DWTT Specimen for Determination of Steel NDT from Pipe of Diameter Less than DN500
}

\author{
M Ben Amara, Julien Capelle, Z Azari, G Pluvinage
}

\section{To cite this version:}

M Ben Amara, Julien Capelle, Z Azari, G Pluvinage. Use of a Ring DWTT Specimen for Determination of Steel NDT from Pipe of Diameter Less than DN500. Journal of Failure Analysis and Prevention, 2016, 16 (6), pp.941-950. 10.1007/s11668-016-0194-y · hal-02972662

\section{HAL Id: hal-02972662 \\ https://hal.science/hal-02972662}

Submitted on 20 Oct 2020

HAL is a multi-disciplinary open access archive for the deposit and dissemination of scientific research documents, whether they are published or not. The documents may come from teaching and research institutions in France or abroad, or from public or private research centers.
L'archive ouverte pluridisciplinaire HAL, est destinée au dépôt et à la diffusion de documents scientifiques de niveau recherche, publiés ou non, émanant des établissements d'enseignement et de recherche français ou étrangers, des laboratoires publics ou privés. 


\title{
Use of a Ring DWTT Specimen for Determination of Steel NDT from Pipe of Diameter Less than DN500
}

\author{
M. Ben Amara ${ }^{1}$ J. Capelle ${ }^{1}$, Z. Azari ${ }^{1}$ G. Pluvinage ${ }^{2}$ \\ ${ }^{1}$ ENIM 57078 METZ (France) \\ ${ }^{2}$ FM.C 57530 Silly sur Nied (France)
}

\begin{abstract}
It has become recognized that the drop weight tearing test (DWTT) energy better represents the ductile fracture resistance of pipe steels since it utilizes a specimen that has the full thickness of the pipe and has a fracture path long enough to reach steady-state fracture resistance. However, the API 5L code does not require it for pipe sizes less than DN500.

The aim of this paper is:

to propose a DWTT specific to small diameter pipes based on a new specimen, the Ring Drop Weight Tearing Test (RDWTT) specimen,

to evaluate the transition temperature $T_{t}$, DWTT and nil ductility temperature (NDT) of the pipe steel API5L X65,

to introduce the transition temperature $T_{t, \text { DwTT }}$ in the Transition Temperature Material Master Curve (TTMC) of the API5L X65 steel,

to compare the prediction of the crack ductile extension in a pipe based on the RDWTT's energy and crack tip opening angle (CTOA) in the case of the steel API5L X65.
\end{abstract}

Keywords Ring specimen, NDT, constraint, crack extension

\section{INTRODUCTION}

The Drop Weight Tear Test (DWTT) is an impact test used primarily to determine the nil ductility transition temperature or NDT of ferritic steels. The test consists of subjecting the specimen to a single impact load at a progression of selected temperatures. The impact load is delivered by a guided, free-falling weight with energy of 340 to $1630 \mathrm{~J}$ according to the yield strength of the steel to be tested. A stop is employed to prevent deflection of more than a few millimeters.

In accordance with the API RP 5L3 specification [1], the DWTT specimens have a size of $76.2 \mathrm{~mm} \times 305 \mathrm{~mm} \times \mathrm{B}$ (B is pipe thickness) in the transverse-longitudinal (T-L) direction. A pressed notch, a chevron notch or an electrical discharge wire-cut notch is machined into the specimens. It has become recognized that the DWTT better represents the ductile fracture resistance of pipe steels since it utilizes a specimen that has the full thickness of the pipe and has a fracture path long enough to reach steady-state fracture resistance.

When plotting the DWTT fracture energy versus temperature, one distinguishes the following types of fracture:

Brittle initiation followed by brittle propagation at temperature $\mathrm{T}<\mathrm{FITT}$

Ductile initiation followed by brittle propagation for FITT $<\mathrm{T}<\mathrm{FTE}$

Ductile initiation followed by ductile propagation for $\mathrm{FTE}<\mathrm{T}<\mathrm{FPT}$

Plastic collapse T> FPT 
with (FITT) the fracture initiation transition temperature, (FTE) the fracture propagation transition temperature or fully elastic transition temperature and (FPT) the fully plastic transition temperature.

Brittle fracture initiation is prevented in pipe steel by ensuring that the service temperature $T_{s}$ is higher than reference temperature $\mathrm{RT}_{\mathrm{t}}$ plus a margin $\Delta \mathrm{T}$ :

$$
T_{s} \geq R T_{t}+\Delta T
$$

The service temperature is conventionally defined by codes or laws according to the country where the structure or the component is built or installed. The reference temperature is associated with transition temperatures obtained from Charpy tests $\mathrm{T}_{\mathrm{K} 27}$, fracture mechanics $\mathrm{T}_{0}$ or DWTT specimens $\mathrm{T}_{\mathrm{t}, \text { DWTT }}$.

Brittle fracture propagation is prevented by specifying a minimum toughness to ensure that the pipeline steel is on the upper shelf of the transition curve at the minimum operating temperature, i.e. the fracture propagation transition temperature (FTE) of the steel is less than the minimum operating temperature. A large amount of correlation with full-scale behaviour has concluded that the FTE can be taken to correspond to the temperature at which a DWTT specimen exhibits an $85 \%$ shear area fracture. This requirement ensures that the line pipe steel will not sustain a propagating brittle fracture. This temperature is generally called the NDT and :

$$
\mathrm{FTE}=\mathrm{T}_{\mathrm{NDT}}
$$

Other definitions of the NDT can be found in the literature :

NDT is the temperature at which the crystallinity is $85 \%$, called $\mathrm{T}_{\mathrm{NDT}}$ or NDT [1].

NDT corresponds to a conventional value of energy (generally $40 \mathrm{~J}$ ) called $\mathrm{T}_{\mathrm{t}}$, DWTT.

These definitions are used if the fracture appearance is without slant fracture (DWTT) and with abnormal fracture.

The NDT has several uses:

it can be introduced as a reference temperature [2] in the design criterion given by Eq.(1) and then $\mathrm{RT}_{\mathrm{t}}=\mathrm{NDT}$,

it is used as a reference temperature in the Material Failure Master Curve (MFMC) based on fracture toughness $K_{I c}=f(T)$ or fracture resistance $K_{I R}=f(T)$ [2]. The $K_{I c}=f(T)$ curve is a lower envelope to all of the fracture toughness tests loaded at quasi-static rates. The $\mathrm{K}_{\mathrm{IR}}=\mathrm{f}(\mathrm{T})$ curve is a lower envelope to all data that include quasi-static initiation, dynamic initiation, and crack arrest toughness results.

$$
\begin{aligned}
& K_{I c}=36.5+3.804 \exp \left[0.036\left(T-T_{N D T}+56\right)\right] \\
& K_{I R}=29.5+1.344 \exp \left[0.026\left(T-T_{N D T}+89\right)\right]
\end{aligned}
$$

The DWTT exhibits the following problems:

it needs large specimens which are not easy to extract from small diameter pipes,

for reasons that are not clear, ISO/API 3183/5L does not require it for pipe sizes less than DN500. Although it is stated that "...sufficient shear-fracture area...is an essential pipebody property to ensure the avoidance of brittle fracture require DWTTs on small-diameter pipe, propagation in gas pipelines", DWTT is only - by agreement - for sizes of DN500 and above.

According to API 1996 [1], a valid DWTT doesn't accept a mixed fracture surface appearance, i.e. a ductile initiation followed by brittle propagation. This fracture appearance 
of invalid specimens is called an abnormal fracture appearance. The abnormal fracture appearance is caused by the change of stress state and dynamic effect during crack propagation and is impossible to avoid by modifying the notch shape and/or the test method [3]. This fracture type corresponds to the intrinsic fracture behaviour of materials, and it is not justified to regard specimens exhibiting the third type of abnormal fracture appearance as invalid and to discard them.

It has been found that the CTOA is effective for evaluating a running ductile fracture in a pipe and its use can be complementary to the NDT for this purpose [4]. According to [5], the CTOA can be evaluated by the DWTT.

The aim of this paper is :

to propose a DWTT specific for small diameter pipes using a ring specimen,

to evaluate $\mathrm{T}_{\mathrm{t}, \mathrm{RDWTT}}$ and $\mathrm{T}_{\mathrm{NDT}}$ of the pipe steel API5L X65,

to introduce these transition temperatures in the Transition Temperature Master Curve

(TTMC) of the API5L X65 steel,

to compare the prediction of the crack ductile extension in a pipe based on the DWTT energy and CTOA in the case of the steel API5L X65 .

\section{MATERIAL AND ITS TRANSITION TEMPERATURES}

The studied material is API X65 pipe steel with ferrite pearlite microstructure. Its typical chemical composition is given in Table 1 and its mechanical properties at room temperature are given in Table 2 .

Table 1. Typical chemical composition of pipe steel API 5L X65 (wt \%) .

\begin{tabular}{|l|c|c|c|c|c|c|c|c|c|c|c|}
\hline & $\mathrm{C}$ & $\mathrm{Si}$ & $\mathrm{Mn}$ & $\mathrm{P}$ & $\mathrm{S}$ & $\mathrm{Mo}$ & $\mathrm{Ni}$ & $\mathrm{Al}$ & $\mathrm{Cu}$ & $\mathrm{V}$ & $\mathrm{Nb}$ \\
\hline min. & 0.05 & 0.15 & 1.00 & - & - & - & - & 0.01 & - & - & - \\
\hline max. & 0.14 & 0.35 & 1.50 & 0.020 & 0.005 & 0.25 & 0.25 & 0.04 & 0.080 & 0.080 & 0.040 \\
\hline
\end{tabular}

Table 2. Mechanical properties of pipe steel API 5L X65 at $20^{\circ} \mathrm{C}$.

\begin{tabular}{|c|c|c|c|c|c|}
\hline $\begin{array}{c}\text { Yield stress } \\
\mathrm{R}_{\mathrm{e}} \\
(\mathrm{MPa})\end{array}$ & $\begin{array}{c}\text { Ultimate } \\
\text { strength } \\
\mathrm{R}_{\mathrm{m}}(\mathrm{MPa})\end{array}$ & $\begin{array}{c}\text { Elongation } \\
\text { at failure } \\
\mathrm{A} \%\end{array}$ & $\begin{array}{c}\text { Charpy energy } \\
\mathrm{K}_{\mathrm{CV}} \\
(\mathrm{J})\end{array}$ & $\begin{array}{c}\text { Fracture } \\
\text { toughness } \\
\mathrm{K}_{\mathrm{Jc}}\left(\mathrm{MP}{ }^{\mathrm{m}}\right)\end{array}$ & $\begin{array}{c}\text { Hardness } \\
\mathrm{HV}\end{array}$ \\
\hline 465.5 & 558.6 & 10.94 & 285.2 & 280 & 205 \\
\hline
\end{tabular}

Vertical impact tests (IT) have been performed on flat specimens made of API 5L X65 pipe steel at the temperature range $\left[-196^{\circ} \mathrm{C}\right.$ to $\left.20^{\circ} \mathrm{C}\right]$. Specimens have a length of $130 \mathrm{~mm}$, a width of $50 \mathrm{~mm}$ and a thickness of $10 \mathrm{~mm}$. They are extracted from a pipe of outside diameter 219.1 $\mathrm{mm}$ and a thickness of $12.7 \mathrm{~mm}$. The specimen has a $\mathrm{V}$ notch along the tangential direction with a depth $\mathrm{a}=5 \mathrm{~mm}$ and a notch radius of $0.25 \mathrm{~mm}$.

The vertical impact test apparatus is a floor-standing impact system designed to deliver 0.59$757 \mathrm{~J}$ or up to $1,400 \mathrm{~J}$ with an optional high energy system. The apparatus is equipped with a temperature chamber and impact software and data acquisition system to simplify the analysis. The specimen is submitted to vertical impact bending at a speed of $5.5 \mathrm{~m} / \mathrm{s}$ with energy of $1400 \mathrm{~J}$. Tests have been performed at different temperatures in the range $\left[100^{\circ} \mathrm{C}-\right.$ $20^{\circ} \mathrm{C}^{\circ}$ ]. For each test, the load displacement diagram is registered as well the absorbed energy for fracture and the crystallinity of the fracture surface.

The fracture energy $\mathrm{E}_{\mathrm{IT}}$ versus temperature curve is reported in Fig. 1 and fitted with the following relationship: 


$$
E_{I T}=A_{I T}+B_{I T} \tanh \left[\frac{\left(T-C_{I T}\right)}{D_{I T}}\right]
$$

where $A_{I T}, B_{I T}, C_{I T}$, and $D_{I T}$ are constants. $A_{I T}$ represents energy at transition temperature, $D_{\text {IT }}$ is defined at half the jump between the lower and upper shelf, $\mathrm{B}_{\mathrm{IT}}$ is the energy jump between the brittle and ductile plateaus and $\mathrm{C}_{\mathrm{IT}}$ is the temperature range of the energy transition. The transition temperature has been determined at the conventional level of $40 \mathrm{~J}$ and is called $\mathrm{T}_{\mathrm{t}, \mathrm{IT}}$ and also at half the jump between the brittle and ductile plateau and called $\mathrm{T}_{1 / 2, \mathrm{IT}}\left(\mathrm{T}_{1 / 2, \mathrm{IT}}=\right.$ $\left.\mathrm{D}_{\mathrm{IT}}\right)$.

The values of the four constants $A_{I T}, B_{I T}, C_{I T}$ and $D_{I T}$ are reported in Table 3 as well as the transition temperatures $\mathrm{T}_{\mathrm{t}, \mathrm{DWTT}}$ (for a conventional level of $40 \mathrm{~J}$ ) and $\mathrm{T}_{\mathrm{DWTT}}, 50$.

Table 3. Values of constants of Equation (1) for API 5L X65 pipeline steel.

\begin{tabular}{|c|c|c|c|c|c|}
\hline $\mathrm{A}_{\mathrm{IT}}(\mathrm{J})$ & $\mathrm{B}_{\mathrm{IT}}(\mathrm{J})$ & $\mathrm{C}_{\mathrm{IT}}(\mathrm{K})$ & $\mathrm{D}_{\mathrm{IT}}(\mathrm{K})$ & $\mathrm{T}_{\mathrm{t}, \mathrm{IT}}(\mathrm{K})$ & $\mathrm{T}_{1 / 2, \mathrm{IT}}(\mathrm{K})$ \\
\hline 334 & 343 & 23 & 227 & 193 & 227 \\
\hline
\end{tabular}

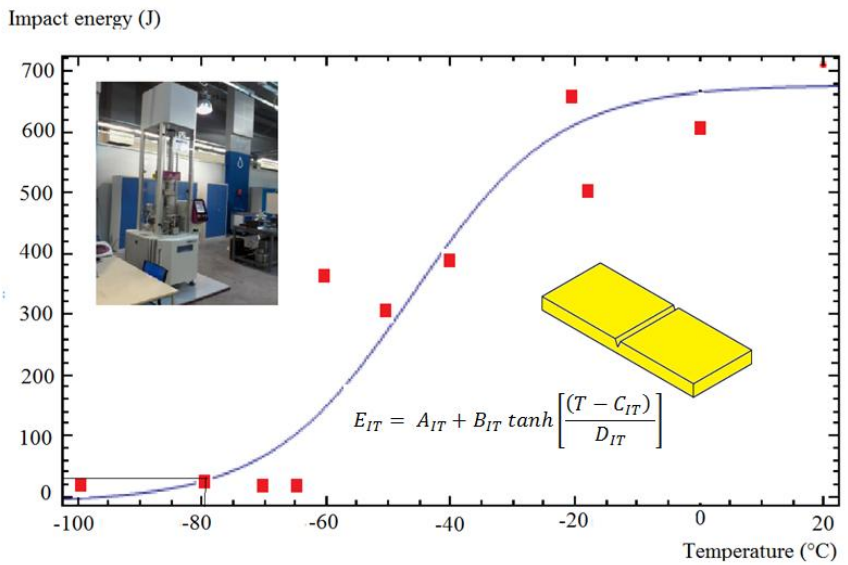

Fig. 1: Impact energy versus temperature curve for a plate specimen made of API 5L X65 pipe and submitted to impact test (IT).

Other transition temperatures for the steel API 5L X65 have also been determined for different Charpy specimens such as Charpy V (V notch, notch radius $\rho=0.25 \mathrm{~mm}$, notch depth $\mathrm{a}=2 \mathrm{~mm}$ ) and Charpy $\mathrm{U}$ specimens like Charpy $\mathrm{U}_{1}$ (U notch, notch radius $\rho=1 \mathrm{~mm}$, notch depth $\mathrm{a}=5 \mathrm{~mm}$ ) and Charpy $\mathrm{U}_{0.5}$ (U notch, notch radius $\rho=0.5 \mathrm{~mm}$, notch depth $\mathrm{a}=$ $5 \mathrm{~mm}$ ) are used. Data are reported in Table 4.

Table 4. Transition temperature and effective T stress for different specimens made of API 5L X65 pipeline steel.

\begin{tabular}{|c|c|}
\hline Notch & $\mathrm{T}_{\mathrm{t}}(\mathrm{K})$ \\
\hline $\mathrm{U}_{1}$ & 150 \\
\hline $\mathrm{U}_{05}$ & 187 \\
\hline $\mathrm{V}$ & 179 \\
\hline
\end{tabular}


The fracture appearance in the ductile-brittle transition consists of three zones and is typical of an abnormal fracture appearance [3]:

- $\quad$ a ductile ligament just under the notch $d_{u n}$,

- $\quad$ a brittle zone of width $d_{b z}$,

- a ductile zone at the opposite of notch $\mathrm{d}_{\text {on }}$.

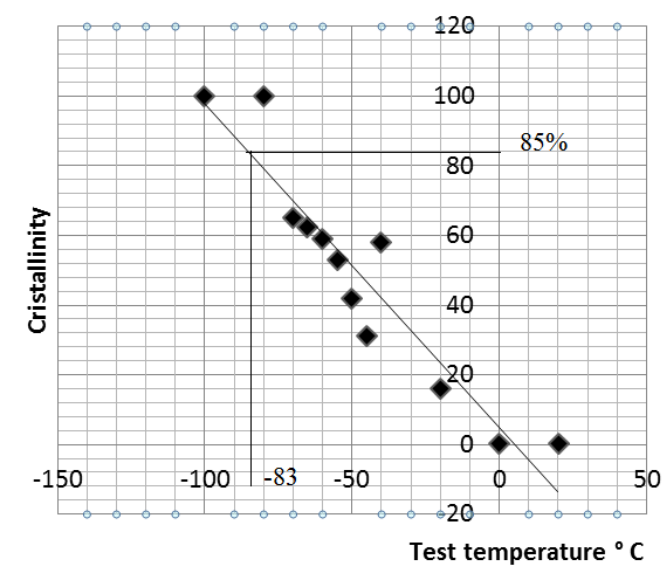

Fig. 2: Crystallinity versus test temperature for API 5L X65 pipeline steel.

The three zones have borders practically parallel to the width direction; therefore, the crystallinity $\mathrm{C} \%$ is simply evaluated by the ratio:

$$
C \%=\frac{d_{b z}}{d_{u n}+d_{b z}+d_{o n}}
$$

The crystallinity versus temperature $\mathrm{C} \%=\mathrm{f}(\mathrm{T})$ is reported in Fig. 2. The transition temperature NDT is evaluated at the conventional level $\mathrm{C} \%=85$ as in Batelle's definition [1]. $\mathrm{T}_{\mathrm{NDT}}=-83^{\circ} \mathrm{C}$ or $190 \mathrm{~K}$ and this value is close to the transition temperature $\mathrm{T}_{\mathrm{t}, \mathrm{TT}} \quad\left(\mathrm{T}_{\mathrm{t}, \mathrm{TT}}=193\right.$ $\mathrm{K})$ defined at the conventional level of $40 \mathrm{~J}$.

\section{NEW SPECIMENS FOR DWTT ON SMALL DIAMETER PIPE}

The standard threshold diameter for the DWTT (D < DN500) is justified by difficulties in conducting the test on small pipes. Flattened specimens were used, but the effect of the plastic deformation involved flattening and associated changes in properties that could affect the outcome of the test [6].

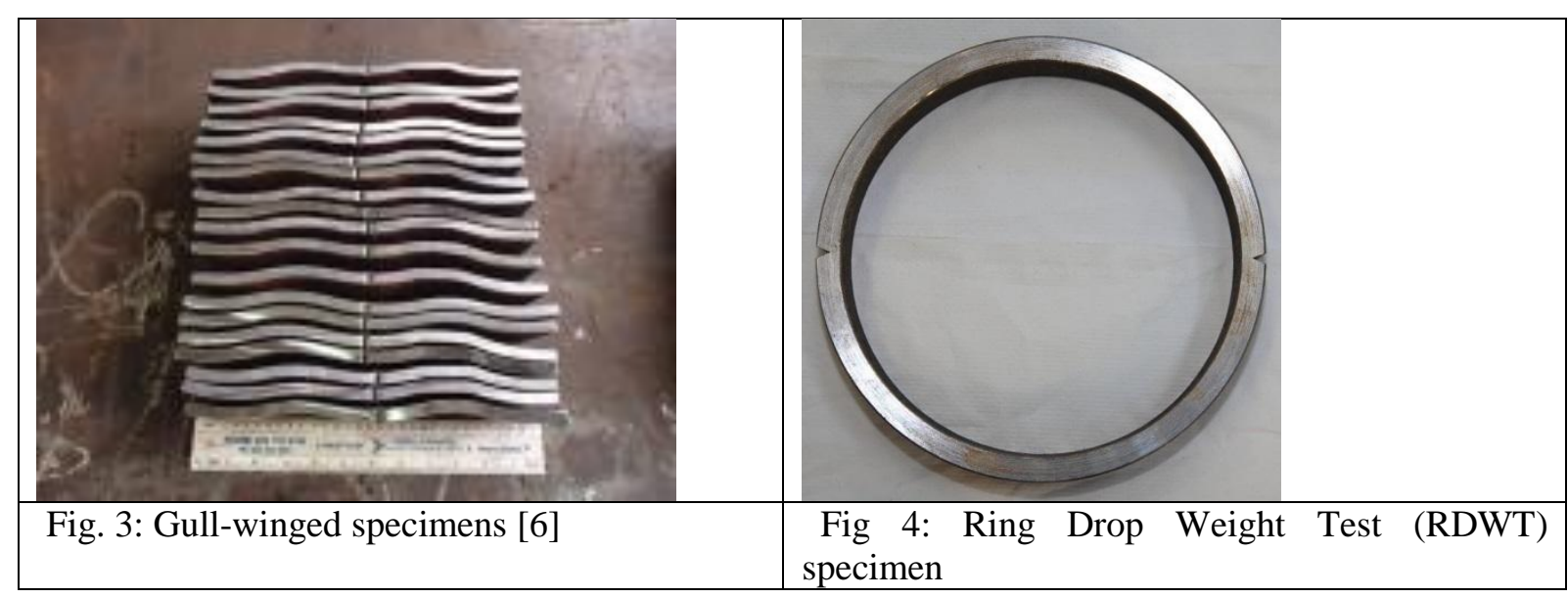


Today, curved DWTT specimens extracted from the pipe are straightened [6-7] to obtain flat specimens as indicated in Fig. 3, and are called gull-winged specimens. This operation inevitably causes additional plastic deformation and may change the fracture propagation behaviour. In order to overcome this difficulty, a ring-notched specimen is proposed. The advantage of this specimen is to avoid the flattening operation and reduce the chipping time and cost. The use of a notched specimen makes it possible to test seam welded pipes by locating the notch in the weld zone. The ring has the same diameter and thickness as the pipe, respectively $\mathrm{D}=220 \mathrm{~mm}$ and $\mathrm{t}=12.5 \mathrm{~mm}$, and its width is $30 \mathrm{~mm}$. Two opposite $\mathrm{V}$ notches are machined for a seamless pipe, only one for a seam-welded pipe (Fig. 4).

The notch is along the longitudinal direction with a depth $\mathrm{a}=5 \mathrm{~mm}$ and a notch radius of 0.25 $\mathrm{mm}$. The specimen is impacted with the same drop-weight apparatus and the same condition (energy, loading rate). It is called the Ring Drop Weight Test (RDWT) specimen.

\section{TRANSITION TEMPERATURE $T_{\text {T,DWTT }}$ AND $T_{\text {NDT }}$ OF X65 STEEL DETERMINED ON RING SPECIMEN}

Registration of the load-displacement and energy displacement diagrams is made during tests on the ring specimens. Two examples of such registrations are presented in Fig. 5 (a-b). In the first example, tests have been performed at $20^{\circ} \mathrm{C}$ for which the fracture is ductile. The second example is a test conducted at $-180^{\circ} \mathrm{C}$ for which the fracture is brittle. For ductile fracture, several oscillations occur, caused by loss of contact of the impactor just after the maximum peak, generated by a stress wave due to impact. For brittle fracture, several peaks appear before the maximum peak, generated by impact waves. Therefore the fracture energy is difficult to determine on load-displacement diagrams. To overcome this difficulty, a video is recorded during the test and the time to fracture is determined. This time is reported on the energy-time record and gives the DWTT impact energy.

The fracture energy versus temperature curve is reported in Fig. 6 and fitted with the following relationship:

$$
E_{R D W T T}=A_{R D W T T}+B_{R D W T T} \tanh \left[\frac{\left(T-D_{R D W T T}\right)}{C_{R D W T T}}\right]
$$

where $A_{R D W T T}, B_{R D W T T}, R_{\text {RDWTT }}$, and $D_{\text {RDWTT }}$ are constants which have a similar meaning to those in Eq. (6). The values of the four constants $A_{\text {RDWTT }}, B_{\text {RDWTT }}, R$ RDWTT, and $D_{\text {RDWTT }}$ are reported in Table 5 as well as the transition temperatures $T_{t, R D W T T}$ and $T_{1 / 2}$, RDWTT at half the jump between the brittle and ductile plateaus.

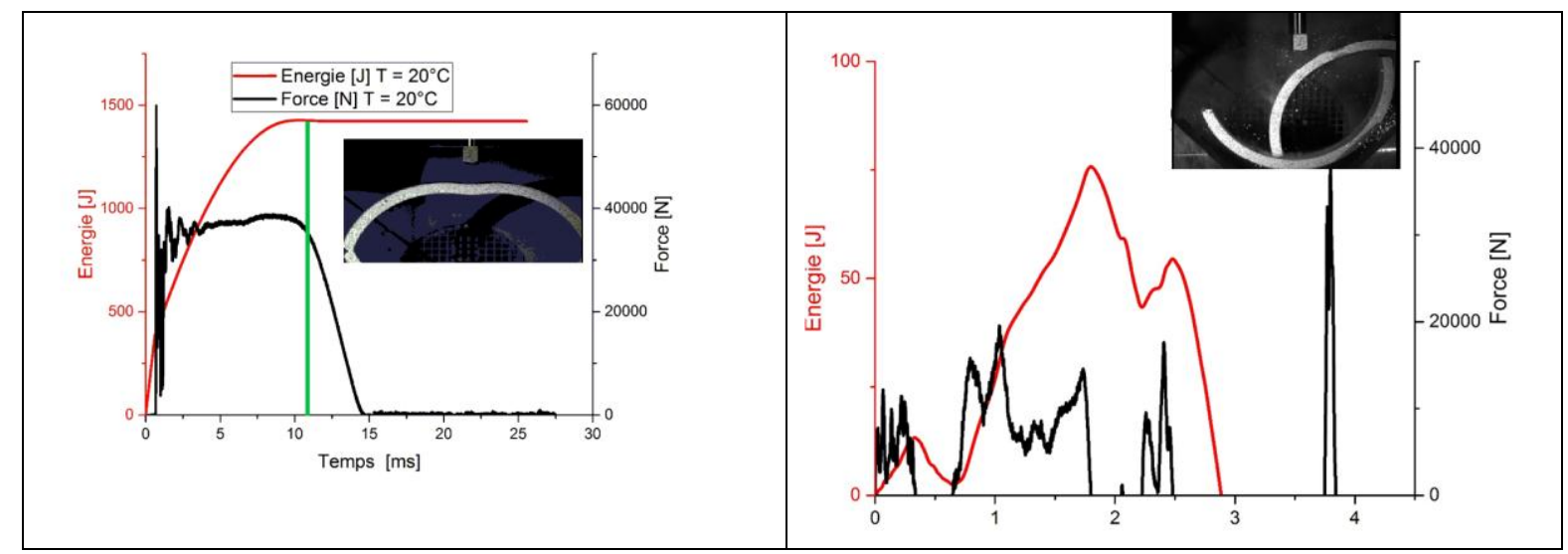


Fig. 5 a: Load-time and energy-time diagram for a drop weight tearing test. Ductile fracture at $20^{\circ} \mathrm{C}$, critical time $10.4 \mathrm{~ms}$.
Fig. 5 b: Load-time and energy-time diagram for a drop weight tearing test. Brittle fracture at $-180^{\circ} \mathrm{C}$, critical time $2.4 \mathrm{~ms}$.

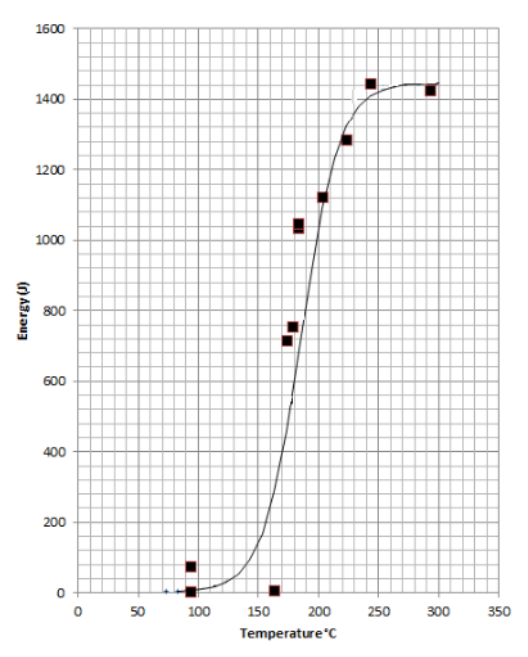

Fig. 6: RWTT fracture energy versus temperature. Evaluation of the transition temperature $\mathrm{T}_{\mathrm{t}, \mathrm{DWTT}}$

Table 5. Values of constants of Equation (6) for API 5L X65 pipeline steel

\begin{tabular}{|c|c|c|c|c|c|}
\hline $\begin{array}{c}\mathrm{A}_{\text {DWTT }} \\
(\mathrm{J})\end{array}$ & $\mathrm{B}_{\text {DWTT }}(\mathrm{J})$ & $\mathrm{C}_{\text {DWTT }}(\mathrm{K})$ & $\mathrm{D}_{\text {WTTT }}(\mathrm{K})$ & $\mathrm{T}_{\mathrm{t}, \text { RDWTT }}(\mathrm{K})$ & $\mathrm{T}_{1 / 2, \text { RDWTT }}(\mathrm{K})$ \\
\hline 724 & 721 & 31 & 180 & 124 & 180 \\
\hline
\end{tabular}

The transition temperature $T_{t, \text { DWTT }}$ is evaluated at the conventional level of $40 \mathrm{~J}_{\text {. }} \mathrm{T}_{\mathrm{t}, \mathrm{DWTT}}$ and $\mathrm{T}_{1 / 2}$,RDWT for the API X65 steel are given in Table 6 respectively for plate and RDWTT.

Table 6: $\mathrm{T}_{\mathrm{t}, \mathrm{DWTT}}$ and $\mathrm{T}_{\mathrm{NDT}}$ for the API X65 steel respectively for plate and RDWTT.

\begin{tabular}{|c|c|c|c|c|}
\hline \multicolumn{2}{|r|}{ Plate } & \multicolumn{2}{|l|}{ RDWTT } & Charpy \\
\hline $\mathrm{T}_{\mathrm{t}, \mathrm{IT}}$ & $\mathrm{T}_{1 / 2, \mathrm{IT}}$ & $\mathrm{T}_{\mathrm{t} \text {,RDWTT }}$ & $\mathrm{T}_{1 / 2, \text { RDWTT }}$ & $\mathrm{T}_{\mathrm{k} 27}$ \\
\hline 227 & 225 & 124 & 180 & 179 \\
\hline
\end{tabular}

From Table 6, it appears that the transition temperature for the drop weight test is very sensitive to the specimen geometry and loading mode. Therefore, the best choice for the design of a structure like a pipe under service pressure needs to be made by a criterion and a method. According to [8], the test specimen is chosen from those which provide a plastic constraint close to that of the structure. This is given by using the Transition Temperature Master Curve (TTMC).

\section{PLASTIC CONSTRAINT IN A RING SPECIMEN}

Constraint is defined as the resistance of a structure against crack-tip plastic deformation. There are two ways to define the constraint:

i) analysis of modification of the crack tip distribution by geometrical or loading parameters,

ii) analysis of the plastic zone size after the same kind of modifications. 
If we compare the stress distribution obtained in a reference situation (generally small-scale yielding) with another general one, the stress distribution is modified in two ways: there is a shift of the stress distribution and a small rotation. These modifications of the stress distribution are used as transferability parameters. The shift of the stress distribution is used to define several plastic constraints. In the literature, we can note the following constraint parameters: the plastic constraint factor L [9], the stress triaxiality $\beta$ [10], the $\mathrm{Q}$ parameter [11], T stress [12], and $\mathrm{A}_{2}$ [13].

For a crack, Larson et al. [14] have suggested describing the elastic stress field at the crack tip by three terms and introduce for the first time the $\mathrm{T}$ term as the second one of the series as a constraint parameter:

$\sigma_{\mathrm{ij}}=\frac{\mathrm{K}_{\mathrm{ij}}}{\sqrt{2 \pi r}} \mathrm{f}_{\mathrm{ij}}(\theta)+\mathrm{T} \delta_{1 \mathrm{i}} \delta_{1 \mathrm{j}}+O \sqrt{r}$

Therefore, ideally $\mathrm{T}$ stress is a constant stress which acts along the crack direction and shifts the opening stress distribution according to the sign of this stress. In reality, $\mathrm{T}$ is not constant as it is in theory. For short cracks, the distribution of the $\mathrm{T}$ stress is stabilized after some distance. For long cracks, $\mathrm{T}$ increases linearly with the ligament, except in a region close to the crack tip. To avoid this dependence of the $\mathrm{T}$ stress on distance, it is attractive to use a conventional definition of the effective T stress. Using the volumetric method, Hadj Meliani et al. [12] suggested defining the effective $T$ stress as the corresponding value in the $T$ stress distribution for a distance equal to the effective distance $X_{\text {ef }}$ defined from the Volumetric Method [15].The stress distribution ahead of a crack tip depends on the polar angle. However, for some particular $\theta$ angles, the $\mathrm{T}$ stress is given by particular values of the difference between the opening stress $\sigma_{\mathrm{yy}}$ and the stress parallel to the crack $\sigma_{\mathrm{xx}}$.

Particularly for $\theta=0$, the T stress is given by:

$$
T=\left(\sigma_{\mathrm{xx}}-\sigma_{y y}\right)_{\theta=0}
$$

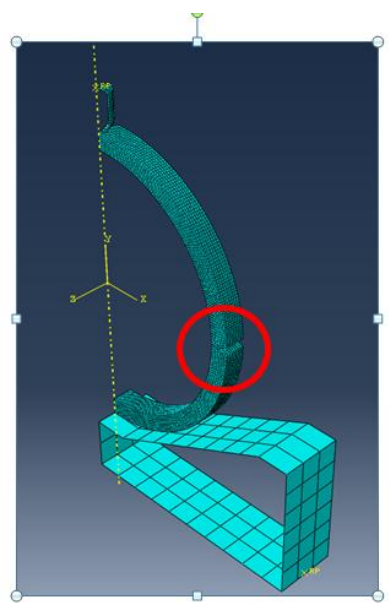

Fig. 7: Impact point, notch location and mesh of the Ring Drop Weight Tear Test (RDWTT) specimen in the finite element method.

Equation (9) is the basis of the so-called stress difference method, which was proposed by Yang et al. [16]. The stress distribution in the direction $\theta=0$ is generally computed by the finite element method (Fig. 7). The material response to loading is assumed to follow Hooke's Law at temperatures below the NDT. This stress distribution near the notch tip exhibits three zones [14]:

zone 1 - the stress increases until its maximum, 
zone 2 - the stress decreases in the region $\mathrm{X}_{\max }<\mathrm{x}<\mathrm{X}_{\mathrm{ef}}$,

zone 3 - for $x$ greater than the effective distance $X_{\text {ef }}$, the stress distribution is governed by the Notch Stress Intensity Factor and is a power function of the distance.

The elastic maximum stress computed by FEM with a static load is related to a stress concentration factor of $k_{t}=1.95$. The impact point and the notch location are given in Fig. 7 . Stress distribution near the notch tip has been computed by the finite element method with an impact load of $55.39 \mathrm{~kg}$, initial speed $5.5 \mathrm{~m} / \mathrm{s}$ and height of $1.5 \mathrm{~m}$. T stress values have been computed using the stress difference method [16]. The effective distance $X_{\text {ef }}$ has been determined using the volumetric method [14]. This effective distance makes it possible, by a graphical procedure described in Fig. 8, to obtain the critical effective T stress for an RDWTT specimen.

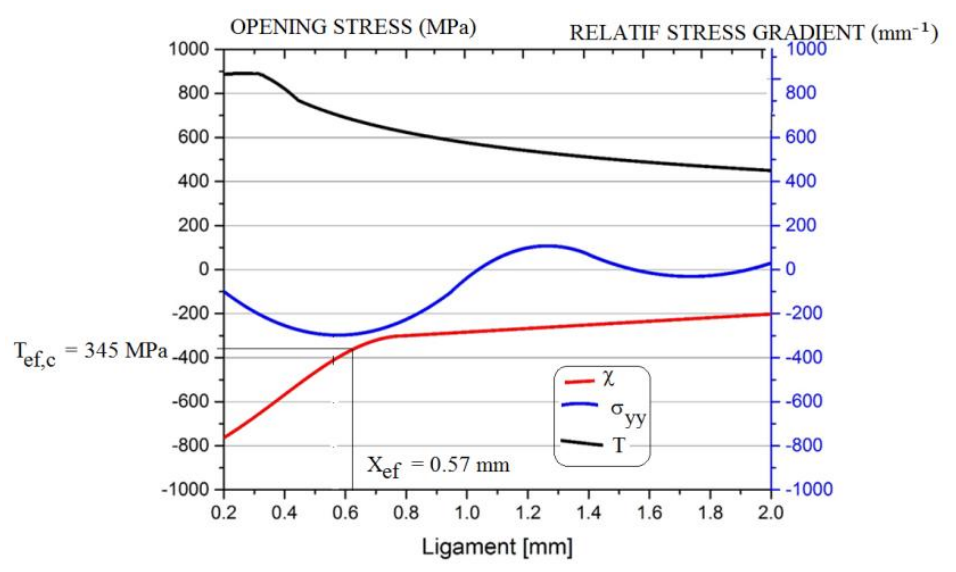

Fig. 8: Stress distribution at notch tip of a Ring Drop Weight Tear Test (RDWTT) specimen. Diameter $\mathrm{D}=219 \mathrm{~mm}$, thickness $\mathrm{t}=12.5$, impact load $55.396 \mathrm{~kg}$, initial speed $5.5 \mathrm{~m} / \mathrm{s}$ and height $1.5 \mathrm{~m}$.

The value of $\mathrm{T}_{\mathrm{ef}, \mathrm{c} \text { for }}$ a Ring Drop Weight Tear Test (RDWTT) specimen for a critical load at temperature equal to the NDT is $\mathrm{T}_{\mathrm{ef}, \mathrm{c}}=345 \mathrm{MPa}$.

\section{INFLUENCE OF CONSTRAINT ON TRANSITION TEMPERATURE}

We have seen previously that the transition temperature is very sensitive to the specimen geometry and loading mode through the plastic constraint and the Transition Temperature Master Curve (TTMC). Wallin [17] has established that the reference temperature $\mathrm{T}_{0}$ in the Material Failure Master Curve is constraint-dependent. $\mathrm{T}_{0}$ is the transition temperature corresponding to a conventional value of fracture toughness of $100 \mathrm{MPa} \sqrt{\mathrm{m}}$. He found a linear relation between the reference temperature $\mathrm{T}_{0}$ and the $T$ stress.

$$
\begin{array}{r}
T_{0}(T)=T_{0, \text { ref }} \text { for } T>0 \\
T_{0}(T)=T_{0, \text { ref }}+\frac{T}{10} \frac{{ }^{\circ} \mathrm{C}}{M P a} \text { for } T<0
\end{array}
$$

$T_{0, \text { ref }}$ is the reference temperature for a reference constraint as obtained for small-scale yielding or for $T_{\text {stress }}=0$. More generally, Wallin [17] proposed: 


$$
T_{0}=T_{0 . T=0}+\frac{A T_{\text {stress }}}{\sigma_{y}}
$$

$A$ is a new parameter. A similar relation was found for X65 pipe steel by Coseru et al. [18] between various transition temperatures $T_{t}\left(T_{t}\right.$, tensile, $T_{0}$, and $\left.T_{K 1 / 2}\right)$ and the critical effective $T$ stress, $\mathrm{T}_{\mathrm{ef}, \mathrm{c}}$.

$$
T_{t}=T_{t . T e f, c=0}+a T_{e f, c}
$$

Here, $a$ is a material constant. This equation represents the Material Transition Temperature Master Curve (MTTMC) $\mathrm{T}_{\mathrm{t}}=\mathrm{f}\left(\mathrm{T}_{\mathrm{ef}, \mathrm{c}}\right)$, which is the key to determining the appropriate reference transition temperature by comparison with the structure transition temperature (Fig. 9).

The value of the critical effective $\mathrm{T}$ stress $T_{e f, c}$ determined on RDWTT specimens at $\mathrm{T}_{\mathrm{t}, \mathrm{RDWT}}=$ $124 \mathrm{~K}$, is $-345 \mathrm{MPa}$. This value is reported on the Material Transition Temperature Master Curve obtained by Coseru et al. [18] on X65 pipe steel with data concerning tensile, CT Charpy $\mathrm{U}$ and $\mathrm{V}$ specimens transition temperature, as can be seen in Table 7 and reported in Fig. 9.

Table 7: Transition temperature obtained with different specimens made of X65 pipe steel.

\begin{tabular}{|c|c|c|}
\hline Notch & $\mathrm{T}_{\mathrm{ef}}(\mathrm{MPa})$ & $\mathrm{T}_{\mathrm{t}}(\mathrm{K})$ \\
\hline $\mathrm{U}_{1}$ & -244.2 & 150 \\
\hline $\mathrm{U}_{05}$ & -228.1 & 187 \\
\hline $\mathrm{V}$ & -230.8 & 179 \\
\hline $\mathrm{CT}$ & -330 & 156 \\
\hline Tensile & -510 & 123 \\
\hline RDWTTT & -345 & 124 \\
\hline
\end{tabular}

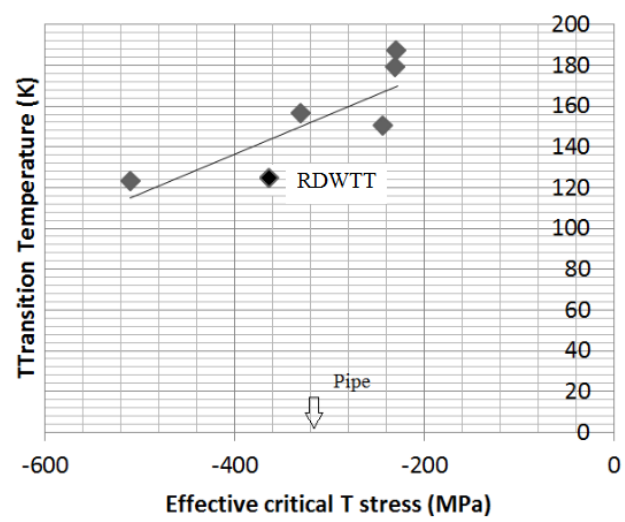

Fig. 9: Position of the transition temperature $T_{t}$, DwTT on the Transition Temperature Master Curve.

This pipe is made of API 5L X52, the pipe has a diameter $\mathrm{D}=611 \mathrm{~mm}$ and a thickness $\mathrm{t}=11$ $\mathrm{mm}$. This pipe exhibits a surface crack of depth $\mathrm{a}=\mathrm{t} / 2$ and aspect ratio $\mathrm{a} / \mathrm{c}=0.2$. A value of $T_{e f, c}=-329 \mathrm{MPa}$ has been found. The pipe has a diameter greater than $500 \mathrm{~mm}$ but the 
obtained value can be considered representative of the constraint obtained on a pipe with diameter in the range [400-800] $\mathrm{mm}$. Therefore, it can be concluded that the RDWTT test is a representative test to determine the transition temperature of a pipe submitted to internal pressure. One notes that the use of the Charpy V transition temperature is a more conservative approach and induces a shift of the minimum service temperature of $26 \mathrm{~K}$.

\section{THE USE OF RDWTT FRACTURE ENERGY FOR DETERMINATION OF ARREST PRESSURE IN A PIPE}

Gas pipeline fracture initiation is usually followed by extended running crack propagation. Such disasters lead to significant financial loss and should be avoided as much as possible or confined to a short portion of the pipe. Therefore, an important question is whether and when the fracture will self-arrest.

Even if brittle crack propagation can be successfully avoided by using high toughness steel, the running ductile fracture remains the most important failure mode in modern gas pipelines. It occurs when driving force energy, caused by internal pipe pressure, overcomes the crack propagation toughness. On the basis of wide-ranging experimental results on full-scale burst tests, Maxey [19] established the first and the most frequently used semi-empirical model to express the running ductile fracture propagation in pipelines with the so-called Battelle twocurve method (BTCM).

This model was modified by the High-Strength Line Pipe (HLP) Committee [20], and again extended with more parameters in the Sumitomo version [21]. It was proved [19] that the ratio between the gas decompression wave and crack propagation speed has a major role in the dynamics of crack growth. Indeed, if the crack propagates faster than the decompression wave, the crack tip is always loaded by the initial pressure $\mathrm{p}_{0}$. Otherwise, the crack tip is progressively less and less loaded up to crack arrest.

Gas decompression curve: During the crack propagation process, the gas escapes through the opening created in the wall of the pipe by the crack. Indeed, a decompression wave begins to propagate through the pipe at a speed of the order of 300 to $400 \mathrm{~m} / \mathrm{s}$. A number of models have been developed for predicting the speed of the gas decompression wave. Many of the models assume a one-dimensional (along the pipe axis) and isentropic flow and use the Finite Difference Method (FDM) or the Method of Characteristics (MOC). BTCM is a model which assumes one-dimensional, frictionless, isentropic and homogeneous fluid and uses the Benedict-Webb-Rubin-Starling equation of state with modified constants to estimate the thermodynamic parameters during the isentropic decompression.

According to this one-dimensional flow model analysis and experimental results obtained from shock tube tests, the decompression pressure at crack tip $\mathrm{p}_{\mathrm{d}}$ is given by the relationship:

$$
\frac{p_{d}}{p_{0}}=\left(\frac{V_{d}}{6 V_{a}}+\frac{5}{6}\right)^{6}
$$

where $\mathrm{p}_{0}$ is the initial pressure, $\mathrm{V}_{\mathrm{d}}$ the decompression gas speed, and $\mathrm{V}_{\mathrm{a}}$ the acoustic speed.

\section{HLP crack velocity curve}

In the HLP method [20], the pre-crack Drop Weight Tear Test (DWTT) absorbed energy has been proposed as a better indicator to express the resistance to fracture propagation, as a fracture surface similar to running ductile fracture. The thickness of the DWTT specimen is 
chosen equal to the pipe wall thickness. The crack velocity curve $V_{c}=f\left(p_{d}\right)$ is given by Eq. (14).

$$
V_{c}=0.670 \cdot \frac{\sigma_{0}}{\sqrt{R_{f}}} \cdot\left(\frac{p_{d}}{p_{a}}-1\right)^{0.393}
$$

Fracture resistance $R_{f}$ is taken as the ratio of $D_{\text {DWTT }}$ energy and the pre-cracked test specimen area $A_{\text {DWTT }}$.

\section{CTOA crack velocity curve}

The crack tip opening angle (CTOA) is becoming an accepted property for characterizing the resistance of a material to fracture in cases where there is a large degree of stable-tearing crack extension during the fracture process. For pipelines, the CTOA concept is an alternative to the fracture energy characterizations provided by the Charpy V notch (CVN) and Drop Weight Tear Test (DWTT) for running ductile cracks in pipes. In thin structures under plane stress conditions like pipes, from a stationary crack to a steadily moving one can also involve a transition from flat to slant fracture. The slant fracture is characteristic of the steady-state propagation conditions of running cracks in real pipelines.

A CTOA-based design criterion against crack propagation is usually written in the form [2223]:

$$
\mathrm{CTOA}_{\max }<\mathrm{CTOA}_{\mathrm{c}}
$$

where $\mathrm{CTOA}_{\max }$ is a measure of the maximum crack driving force calculated from a knowledge of the dimensions, material properties and operating conditions of a pipe, and $\mathrm{CTOA}_{\mathrm{c}}$ is the fracture resistance of the material. The use of the CTOA to model the ductile crack propagation of thin structures has been validated by [22].

To simulate crack propagation, the CTOA fracture criterion is introduced in a numerical model using the node release technique. The condition of node release is given by the following equation:

$$
\mathrm{CTOA}_{(\mathrm{par})}=\mathrm{CTOA}_{\mathrm{c}}
$$

where $\mathrm{CTOA}_{(\mathrm{par})}$ is the crack tip opening angle induced by the arrest pressure.

The node release technique is based on the assumption that the crack growth is described by uncoupling nodes at the crack faces, whose acting tractions are exercised as far as the crack opens. Opposed to the CZM [24] approach where this acting traction is reduced progressively by using the traction-separation law, in the CTOA approach the crack tip node exercises the same acting traction as far as the crack tip node is not released. When the CTOA reaches its critical value $\mathrm{CTOA}_{c}$, the representative node of the crack tip is released and a new position of the crack is deduced. Each propagation step corresponds to the size of a mesh element. In this method, the crack evolution depends on the size of the mesh elements around the crack tip, since it governs the amount of the crack advance. 


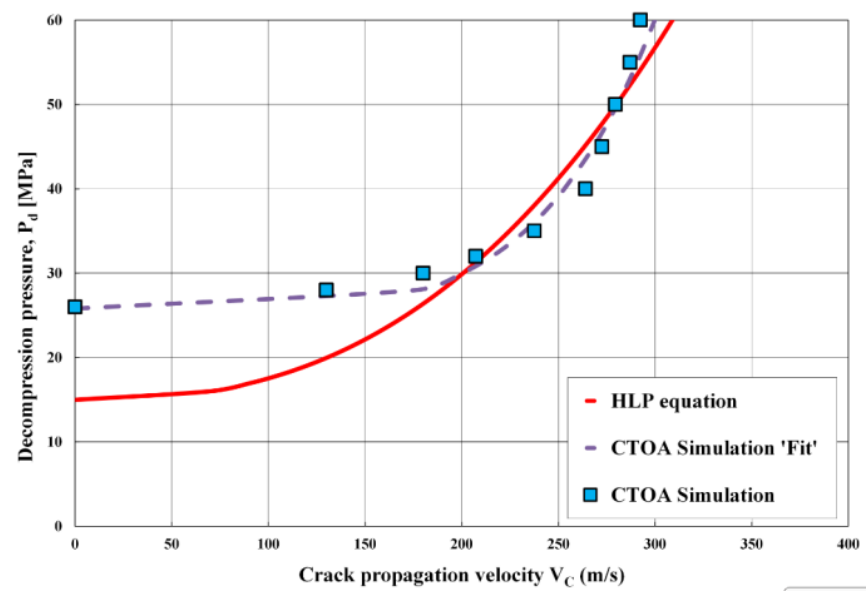

Fig. 8: Crack velocity curve for a pipe under internal pressure. Pipe thickness $19 \mathrm{~mm}$, pipe diameter $355 \mathrm{~mm}$, steel API 5L X65.

Moreover, the advancing process is not really continuous, since a proper iteration scheme is necessary to evaluate the dynamic crack growth during the integration time accurately. The method requires an a priori knowledge of the crack propagation path.

A comparison of the HLP and CTOA methods is presented in Fig. 10 for a pipe of diameter $355 \mathrm{~mm}$ and thickness $19 \mathrm{~mm}$ made of steel API 5L X65. The CTOA value is equal to $20^{\circ}$ according to [23]. The arrest pressure is $27 \mathrm{MPa}$ by the CTOA method and $16 \mathrm{MPa}$ according to HLP. One notes that the HLP method underestimates the arrest pressure (for $V_{C}=0$ ) probably because the resistance to crack extension is overestimated. The DWTT energy consists of two parts: one part for crack initiation and one part for crack propagation. For API $5 \mathrm{~L} \mathrm{X65}$ at $20^{\circ} \mathrm{C}$, the ratio of DWTT energy for fracture initiation to energy for fracture is $32.4 \%$.

\section{CONCLUSION}

Due to the fact that the Drop Weight Tear Test is only, by agreement, for pipe sizes of DN500 and above, it is necessary to propose an alternative test to determine the NDT for low diameter pipes, since it has become recognized that the NDT better represents a reference temperature for the ductile fracture resistance of pipe steels.

This paper proposes the Ring Drop Weight Tear Test specimen, which can be used for any pipe diameter but particularly for small diameter pipes. This kind of specimen is cheap and easy to extract from pipes. It is impacted by a drop-weight apparatus. It provides a transition temperature $T_{t, R D W T T}$ and NDT lower than those obtained on TPB plate extracted from the same pipe. This can be explained by the constraint of the specimen measured by the T stress. After strain rate correction, the NDT of X65 pipe steel is correctly situated on the transition temperature material master curve (TTMC), which represents the linear evolution of the transition temperature with constraint.

The RDWTT energy introduced in the crack velocity curve and obtained according to the HLP model [20] predicts an arrest pressure lower than the CTOA method. This can be explained by the fact that the resistance to crack extension is overestimated when using RDWTT energy. 